\title{
A importância das redes sociais no relacionamento interpessoal de alunos do ensino a distância
}

Recebido em: 03/11/2012 - Aprovado em: 12/11/2012 - Disponibilizado em: 26/12/2012

\section{Resumo}

Este artigo tem a finalidade de abordar a importância das redes sociais no relacionamento interpessoal de alunos de cursos superiores a distância. As redes sociais podem ser utilizadas pelos professores para incentivar os alunos a se conhecerem melhor, com a finalidade de formação de equipes de trabalho por afinidade, visto que possibilita um maior conhecimento do seu colega de curso, podendo até criar relações amistosas entre

\section{Introdução}

As redes sociais virtuais surgiram há mais ou menos 15 anos, com o pioneiro Sixdegrees em 1997, viabilizando a interação entre pessoas na WEB, mas após três anos, por dificuldades em angariar recursos financeiros deixou de prestar serviço à comunidade. Após esse episódio, no período de 2003 a 2006 surgiram algumas redes sociais que conseguiram muito sucesso, algumas atingindo milhões eles, o que facilita a interação para o relacionamento nos estudos. Para abordar essas questões foi feita uma pesquisa, por meio de um questionário com alunos de um curso superior a distância. A fundamentação teórica foi baseada na teoria da psicologia sócio-histórica de Lev S. Vygotsky, in LUCCI (2006).

Palavras-chave: Redes sociais, interação, educação a distância.

de usuários como Orkut, Facebook, MSN, Twiter, entre outras.

Vista essa história, notamos que a WEB tem beneficiado pessoas de todo mundo com sites de relacionamento, ambientes de informação e de aprendizado. As redes sociais virtuais possibilitam o encontro de pessoas e um relacionamento interpessoal mais informal na troca de informações, facilitando, assim, a interação na participação da vida e, por conseqüência um maior conhecimento do outro.

A EAD - Educação a distância leva a possibilidade de formação para os

\footnotetext{
${ }^{1}$ Psicóloga clínica desde 2009. Mestre em Educação, Psicóloga e Pedagoga. Especialista em Educação a Distancia e em Análise Psicodramática na Escola Paulista de Psicodrama (área clínica). Docente do Ensino Superior desde 2002, ministrando disciplinas presenciais em cursos de tecnologia e bacharelado, bem como em Educação a Distância. Docente em nível de Pós Graduação desde 2011. Orientadora de Projetos e de atividades complementares. Possui experiência na área administrativa como Assistente de Direção (área pedagógica). Participou da construção da CPA - Comissão Própria de Avaliação Institucional na Faculdade Radial, atual UniRadial, de 2004 a 2009. Coordenou Capacitação Docente do Colégio e Faculdade Anchieta de 2006 a 2010.
} 
indivíduos das mais restritas regiões do país e do mundo. Este artigo pretende abordar a questão da importância das redes sociais na EAD, por meio da troca de informações pessoais, torna o aluno mais próximo do seu colega de curso e proporciona identificações motivando-os nas escolhas dos colegas que farão parte de seus grupos de estudo e desenvolvimento de projetos ao longo do curso, seja ele qual for.

Nesta pesquisa, especificamente, foi feito um questionário com a intenção de obter uma amostragem de alunos do Curso Superior de Tecnologia em Logística em Educação a Distância da Faculdade Anchieta, atual Anhanguera, na cidade de São Bernardo do Campo, SP. A idéia é de verificar se esses alunos se relacionam em redes sociais e se isso facilita ou não a interação e o relacionamento entre os colegas de curso. Acredita-se que a relevância dessa pesquisa ajudará docentes da EAD a motivarem seus alunos ao encontro com os colegas por meio das redes sociais virtuais, visto que eles não se encontram no dia-a-dia para conheceremse, tornando o trabalho do docente mais fácil no sentido de que os próprios alunos possam formar seus grupos de trabalho, por afinidades.

Portanto, a ideia é que as redes sociais possam facilitar o conhecimento do colega de curso, possibilitando um envolvimento entre os alunos e facilitando o conhecimento do outro e a afinidade para os agrupamentos. Aqui cabe lembrar, que a reflexão por meio das trocas entre os parceiros são momentos significativos no processo ensino-aprendizagem e que, segundo a psicologia sócio-histórica ${ }^{2}$, que tem como base a teoria de Vygotsky (1996), concebe o desenvolvimento humano a partir das relações sociais que a pessoa estabelece no decorrer da vida. Nesse referencial, o processo de ensinoaprendizagem também se constitui nas relações nos diversos contextos sociais, sendo os mais atuais, as redes sociais virtuais.

A EAD é um cenário novo no mundo educacional e necessário devido as grandes oportunidades de estudo que proporciona à sociedade, visto que nem todos tem acesso físico no tempo disposto pelas universidades no estudo presencial. Portanto cada estudo referente a EAD é benéfico e agrega valor aos profissionais que se dedicam a essa forma de propagação do conhecimento. $\mathrm{O}$ professor da EAD pode intervir com situações que atribuam significado aos alunos, tornando a relação amistosa e histórica, entre eles, pois conforme Vygotsky (1982), mais que superar os unilateralismos na análise da relação sujeito-objeto, o importante é buscar compreender as especificidades dessa relação quando sujeito e objeto são históricos e quando a relação entre eles também é histórica.

Observa-se que na abordagem Vygotskyana o homem é visto como alguém que transforma e é transformado nas relações que acontecem em uma determinada cultura. O que ocorre não é uma somatória entre fatores inatos $\mathrm{e}$ adquiridos e sim uma interação dialética, que se dá, desde o nascimento, entre o ser humano e o meio social e cultural em que se insere. Assim é possível constatar que o ponto de vista de Vygotsky (1982) é que o desenvolvimento humano é compreendido

\footnotetext{
${ }^{2}$ http://www.crmariocovas.sp.gov.br/dea_a.php?t=002 acesso em 03/02/2012.
} 
não como a decorrência de fatores isolados que amadurecem, nem tampouco de fatores ambientais que agem sobre o organismo controlando seu comportamento, mas sim como produto de trocas recíprocas que se estabelecem durante toda a vida entre indivíduo e meio, cada aspecto influindo sobre o outro.

Observa-se que nossa história é construída a partir da convivência com o outro. Em um curso de EAD essa convivência fica comprometida e por conseqüência sua história universitária também, visto que o contato com o outro está limitado e a relação em uma rede social pode ajudar na sua aprendizagem a medida que ocorram identificações com sujeitos e suas histórias.

\section{Hipóteses}

Uma rede social é uma estrutura composta por pessoas ou organizações, a qual possibilita aos usuários um relacionamento mais afetivo, visto que compartilharam de informações sobre a vida particular dos colegas de curso.

As instituições de ensino possuem locais para a projeção da EAD, que são plataformas de ensino, das quais podemos destacar o MOODLE e o TELEDUC. Essas plataformas possuem ferramentas para o desenvolvimento das aulas, mas são espaços limitados em aspectos da particularidade do aluno. Já em uma rede social, o aluno pode postar fotografias, comentar suas experiências de vida, enfim, mostrar seu estilo de vida e conhecer o dos seus colegas. Foi pensando na possibilidade de aproximação dos alunos que surgiu a idéia de trabalhar em um artigo sobre a possibilidade de motivar os alunos a trocarem informações nas redes sociais e com isso possibilitar o conhecimento dos seus pares.

\section{Justificativa}

Atualmente os jovens estão muito influenciados pelo uso da internet e envolvidos com seus colegas em redes sociais, tipo Orkut, Facebook, Twiter, Linkedin, MSN, entre outras. O docente por sua vez, também participa de uma rede social, na qual seus alunos podem ter acesso. Esse contato aproxima as pessoas, é o que entendo por estar junto virtual, compartilhar da vida.

Aproveitando-se deste estar junto virtual, poderíamos introduzir textos, filmes, fotos, situações de experiência de vida, entre outros, com a finalidade de proporcionar discussões a respeito de assuntos acadêmicos o que despertaria o interesse dos alunos pelo conhecimento.

A EAD é uma forma de adquirir conhecimento pela internet, isso faz com que os docentes necessitem entrar no mundo virtual dos alunos para acompanhálos. Participar de redes sociais com eles é uma forma de acompanhá-los e motivá-los a conhecerem-se melhor para a formação dos grupos, visto que quase não se encontram no ambiente presencial (somente 20\% do curso).

Escrever sobre o uso de Redes Sociais na EAD vem ao encontro de uma nova comunicação e ajuda os docentes a encontrarem outras ferramentas de motivação para o aluno com este perfil. 


\section{Metodologia}

A pesquisa exploratória será a metodologia utilizada neste trabalho, pois a idéia é proporcionar maior familiaridade com o problema, objetivando torná-lo mais claro e construir hipóteses. Irá envolver levantamento bibliográfico; entrevistas com pessoas que tiveram experiências práticas com o problema pesquisado; análise de exemplos que estimulem a compreensão (GIL, 1996).

A pesquisa foi feita por meio da aplicação de um questionário em uma turma de 47 alunos com um retorno de 22 questionários respondidos, perfazendo $46,8 \%$ do total de alunos da turma. A Faculdade possui 113 alunos matriculados no Curso Superior de Tecnologia em Logística - modalidade EAD, sendo um referencial de $19,4 \%$ do total de alunos na amostragem desta pesquisa.

Foram feitos os seguintes questionamentos aos alunos:

1. Você está cadastrado em uma rede social? (sim, não, porque) Se sim, desde quando?

2. Quais redes sociais mais utilizam?

3. Qual o motivo da escolha por essa(s) rede(s) Social (is)?

4. Quantas vezes por semana disponibilizam para se relacionar na rede social?

5. Considera que a rede social é importante para conhecer melhor os colegas de curso? (sim, não, porque).

6. Qual a importância da rede no relacionamento interpessoal com os colegas?
7. Na rede social, o que chama mais a t e n çã o, c o m r e la çã o a o relacionamento interpessoal geral?

8. Você considera que a rede social seria útil para uso dos docentes da EAD? (sim, não, porque).

9. Em sua opinião, para que finalidades poderiam utilizar a rede?

Observa-se que o artigo tem a característica de uma pesquisa qualitativa, pois o questionário aborda os dados subjetivos, e quantitativos, pois investiga o relacionamento interpessoal, a interação e motivação, apresentando partes que elucidam a rede social mais utilizada por esses alunos.

O desenho deste processo se apoia nos elementos básicos da pesquisa segundo LUNA (2002, p. 16). A partir dos seus conceitos foi verificado:

1. Determinação das informações necessárias.

2. Busca de bibliografia sobre redes sociais.

3. Definição do conjunto de ações que produzam essas informações.

4. Leitura do material bibliográfico para fundamentação teórica e aplicação de questionário.

5. Produção de respostas.

6. Aplicação de questionários para os alunos de uma turma do Curso de Logística a Distância da Faculdade Anchieta, em São Bernardo do Campo, com a finalidade de verificar quais as redes sociais mais utilizadas por eles e o que pensam sobre a importância ou não de conhecer melhor seu colega de curso acessando esses sites de 
relacionamento. Esta pesquisa foi realizada no mês de novembro de 2011.

7. Análise dos resultados.

8. A análise dos resultados foi feita pela tabulação das respostas pela autora e analisada como demonstrado abaixo nos gráficos.

\section{Análise da Pesquisa}

Os dois gráficos abaixo (F1 e F2) mostram que $63 \%$ dos alunos que participaram da pesquisa estão cadastrados em uma rede social e que $13 \%$ deles, ou seja, a maioria, somente há três anos. Podemos deduzir que poucos são os alunos deste curso de EAD que se relacionam em redes sociais.

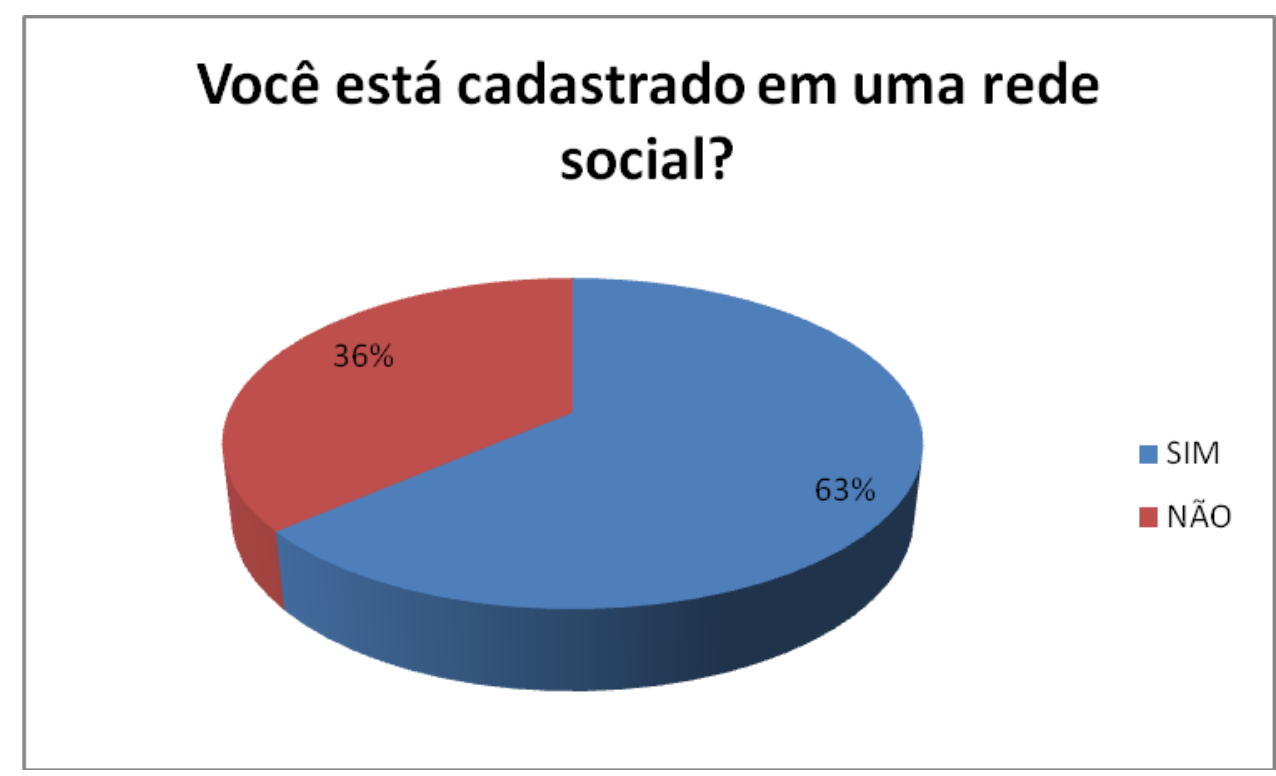

Figura 1 - desenvolvida pela autora em 11/2011

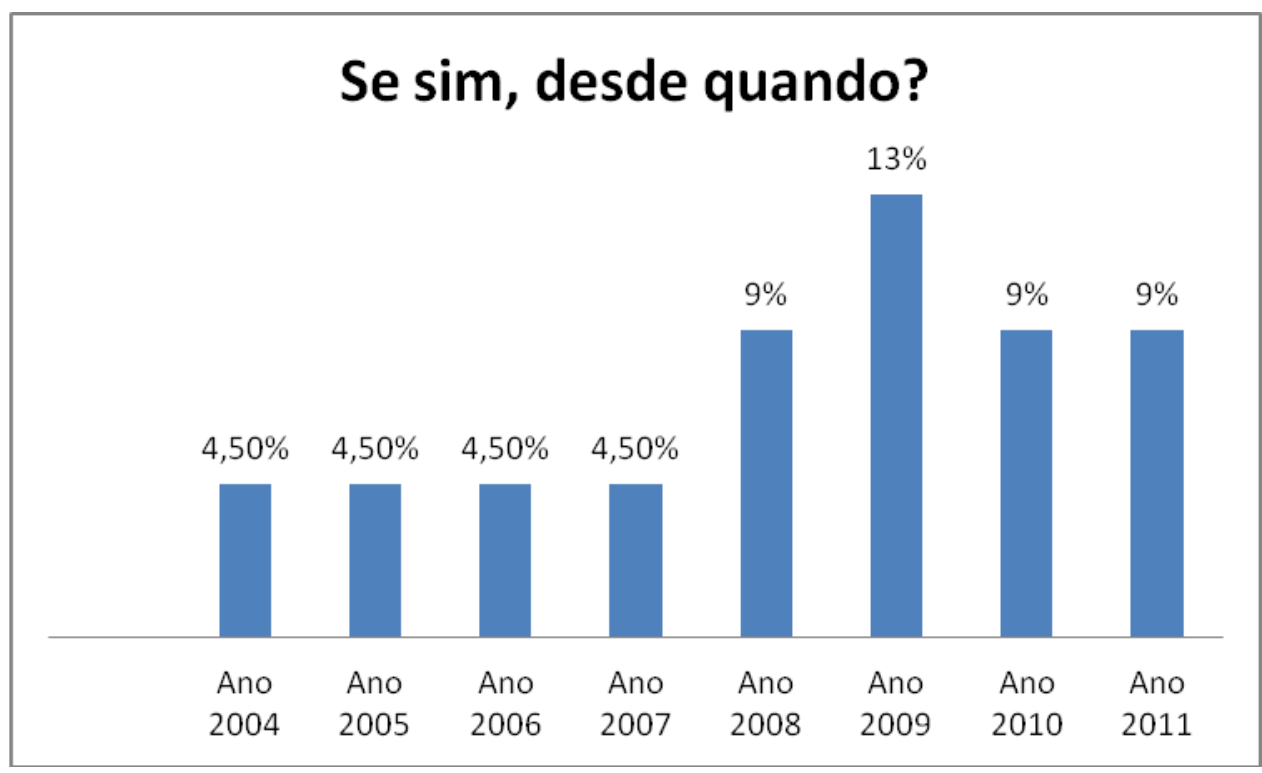

Figura 2 - desenvolvida pela autora em 11/2011 
Observa-se no gráfico abaixo (Figura 3) que as redes sociais mais utlizadas por esses alunos são, Facebook e Orkut com $36 \%$ das respostas e o MSN com $22 \%$.
Aqui podemos observar que os alunos procuram um relacionamento mais social do que de trabalho (Linkedin) ou em voz/ vídeo (Skype).

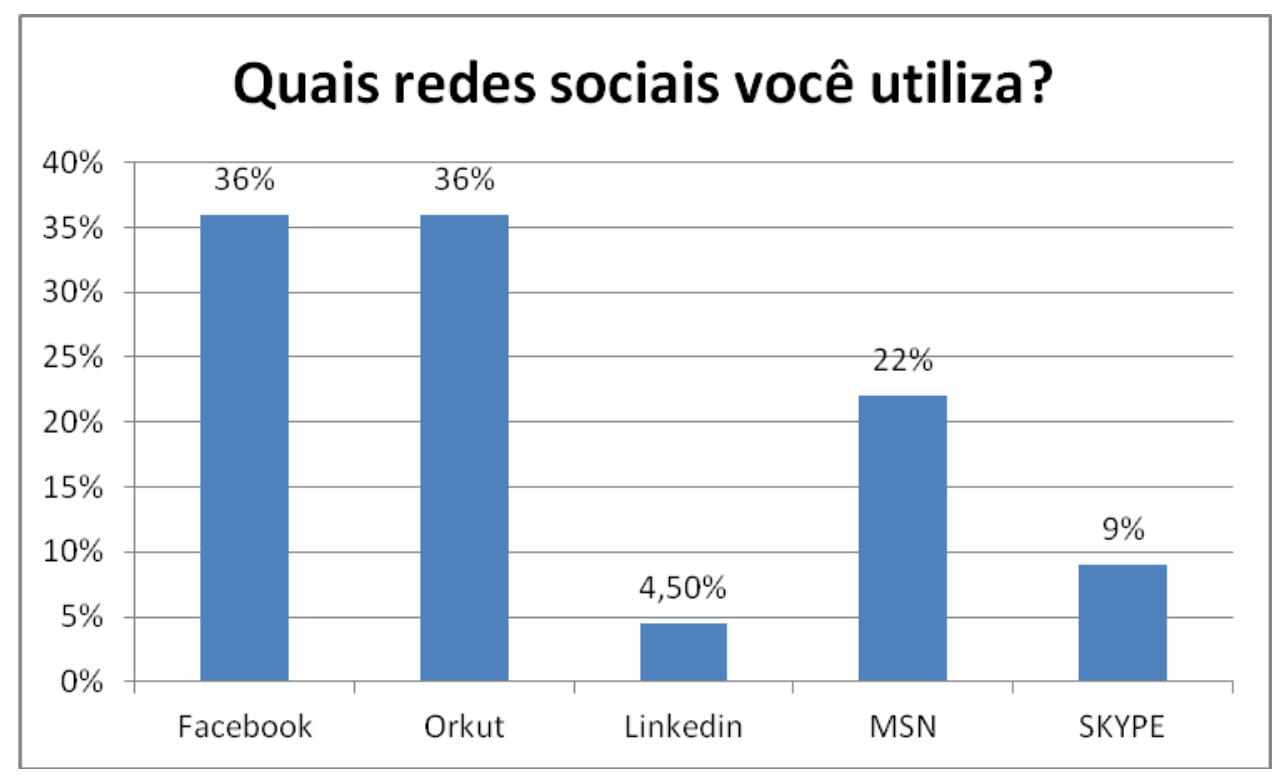

Figura 3 - desenvolvida pela autora em 11/2011

Questão 4 - Qual o motivo da sua escolha por essa rede social?

Dentre as respostas, obtivemos as seguintes: pesquisar; procurar amigos e conhecer as novidades; pela praticidade; conversar com pessoas; simplesmente contato de trabalho; ober um e-mail e utilizar mensagens; facilidades; compartilhamento incomum com amigos e família; facilidades de fazer amigos; ter notícias e reencontrar velhos amigos; utilização mais fácil e rápida; fazer amigos; contato com conhecidos ou não; facilidade para encontrar amigos e comunicar-se em diferentes horários; contatos.

Confirma-se aqui que a maioria dos alunos buscam na rede social um relacionamento social para fazer amigos ou reencontrar antigos amigos, o que constata a teoria Vygotskyana sobre o desenvolvimento humano ser compreendido como produto de trocas recíprocas que se estabelecem durante toda a vida, entre indivíduo e meio, cada aspecto influindo sobre o outro.

No gráfico abaixo (Figura 4), observase que $13 \%$ dos alunos acessam a rede todos os dias e a mesma porcentagem somente uma vez por semana, ficando a média de acessos ou quase nunca em $9 \%$. Essa análise nos mostra que poucos alunos disponibilizam seu tempo para relacionamentos na rede social. 


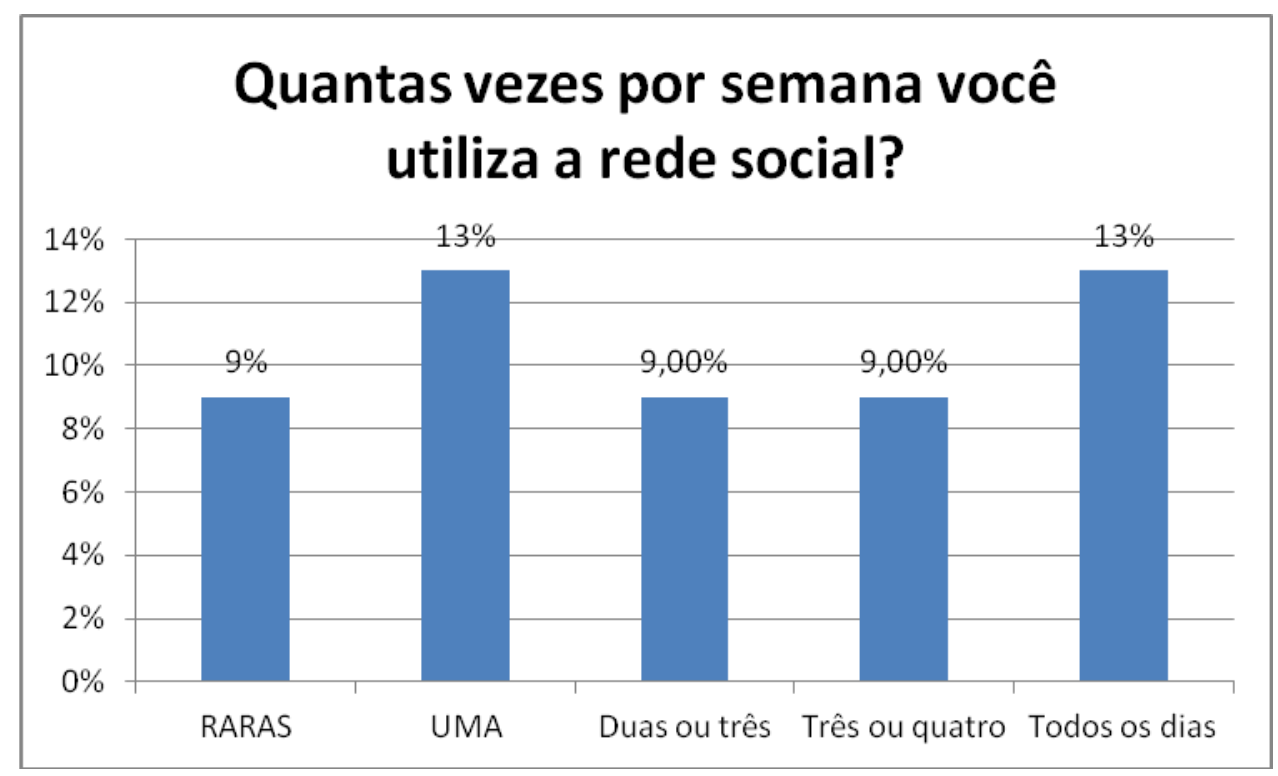

Figura 4 - desenvolvida pela autora em 11/2011

Uma amostra interessante é definida no gráfico abaixo (Figura 5), 54\% do grupo de alunos que participaram da pesquisa não acham que a rede social é importante para conhecer seu colega de curso e $40 \%$ acham que sim. Observa-se aqui uma contradição com relação as respostas apresentadas na questão quatro o que indica que é necessário aprofundar a pesquisa.

\section{Você acha que a rede social é importante para conhecer seu colega de curso?}

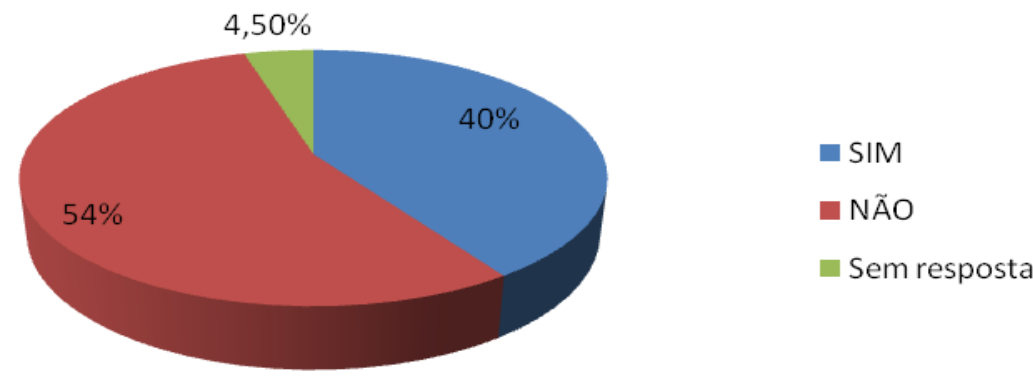

Figura 5 - desenvolvida pela autora em 11/2011

Questão 7 - Se sim, escreva um pouco sobre essa importância no seu relacionamento interpessoal com seus colegas.
Dos $40 \%$ que acreditam que a rede social é importante para o relacionamento interpessoal com seus colegas de curso, observa-se as seguintes explicações: como 
o curso que fazemos é em EAD, quase não conversamos nem nos vemos, nessas redes podemos conversar e compartilhar várias coisas; por termos acesso ao perfil dos colegas, assim conhecemos um pouco mais de seus costumes e valores; porque com um dia por semana de aula, não temos tempo de interagir com os colegas. As pessoas se expõe um pouco mais em suas redes sociais; gosto e perfiro conversar olhando nos olhos; para termos mais contato com os colegas e tirar algumas dúvidas sobre o curso; normalmente nos encontros presenciais nos perocupamos mais com a aula e não temos tempo para as pessoas em particular; importante para além do estudo, obter algumas informações; acho importante porém, estamos sufocados com tantas ferramentas eletrônicas disponíveis; podemos conversar com várias pessoas em vários locais ao mesmo tempo.

Observa-se que a importância aqui relatada pelos alunos está relacionada com as experiências de vida, valores, interação e trocas de conhecimento. O que vem confirmar a teoria Vygotskyana, novamente, de que o desenvolvimento humano acontece a partir das relações sociais que a pessoa estabelece no decorrer da vida.

Questão 8 - O que na rede social mais lhe chama a atenção, com relação ao relacionamento interpessoal?

As respostas apresentadas foram: nas redes sociais nos atualizamos; a rapidez com que a informação se propaga; conhecer quais os ambientes que as pessoas freqüentam; se há compatibilidade familiar entre os colegas; velocidade na comunicação para os que a acompanham diariamente; a acessibilidade; a vida das pessoas, composta dos fatos de seu dia-adia, sua família, passeios e lazer; podemos trocar idéias e informações; facilidade na comunicação; poder mentir sem ninguém lhe questionar; às vezes é bom, mas não dependo desta ferramenta; para localizar amigos distantes; porque tenho pessoas em outro estado e me comunico melhor; a falta de sentimento e atenção, principalmente pela razão de não observar o tempo que o outro está disponibilizando.

Observa-se nessas respostas que os alunos buscam um relacionamento rápido, no qual possam compartilhar informações e ocorrências pessoais com amigos distantes ou até mesmo com familiares, utilizando-se da rede social para ampliar seus contatos.

No quadro abaixo (Figura 6), observamos que a maioria dos alunos diz que a rede social não seria útil aos docentes, $72 \%$ deles e $27 \%$ diz que seria útil. Observa-se nesta pesquisa que a relevância da resposta negativa sobre essa questão não foi investigada, por não estar nas propostas deste artigo, porém desperta uma curiosidade a respeito desse assunto. 


\section{Você acha que a rede social seria útil para uso dos docentes da EAD?}

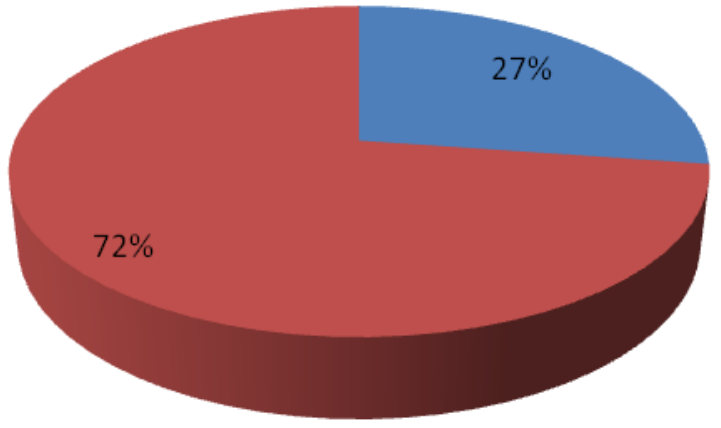

Figura 6 - desenvolvida pela autora em 11/2011

A questão 10 - Se sim, eles poderiam utilizar a rede para que finalidade?

As respostas sobre essa questão foram: divulgar informações sobre o curso ou as matérias; para conhecer melhor seus alunos, assim também teriam mais contato; orientar os alunos; bate-papo; comunicação mais rápida com os colegas; utilizar como fonte de informação e relacionamento; a rede social é algo para se distrair, não acho aplicável em curso ou para estudo; a plataforma de EAD basta para o curso.

Observa-se nessas respostas que os alunos acreditam que a rede social possa proporcionar um melhor conhecimento deles pelos docentes, que na rede teriam mais contato com o professor, poderiam bater papo ou esclarecer dúvidas, porém não acham aplicável para o curso e isso é relevante, pois nos cursos a distância existe uma plataforma de estudo que satisfaz as necessidades educacionais.

\section{Conclusão}

Encerrando as observações adquiridas com esta pesquisa, verifica-se, nas respostas dos alunos que as redes sociais são locais para fazer amigos ou reencontrar antigos contatos. Poucos alunos disponibilizam tempo para entrar na rede social todos os dias, somente $13 \%$, mas $54 \%$ deles acham que a rede social é importante para conhecer seu colega de curso.

Com relação à importância da rede social para os alunos de EAD, tema central deste artigo, observa-se que está relacionada com o conhecimento do colega sobre fatos pessoais, como, experiência de vida, valores, trocas de conhecimento. Neste caso, pode-se afirmar que as redes sociais aproximam as pessoas e facilitam o relacionamento, pois na medida em que se conhece o outro se estabelece uma afinidade, aumentando assim o interesse em aproximar-se desta ou daquela pessoa, para trocar conhecimento ou informações, 
melhorando o relacionamento interpessoal entre os colegas de curso.

Confirma-se a teoria Vygotskyana de que o desenvolvimento humano acontece a partir das relações sociais que a pessoa estabelece no decorrer da vida.

Com essa pesquisa, observa-se, ainda que o aluno não achasse interessante adicionar professores as suas redes sociais, visto que preferem ter um contato maior com os colegas e também porque o contato com professores se dá nas plataformas de EAD. Aqui cabe ressaltar que a relação professor-aluno está no âmbito da disseminação do conhecimento e para isso existe local específico, ficando assim preservada do social, estando claro, nas respostas, que o que esperam do docente são explicações para entendimento do que estão aprendendo, não o contato social.

A relevância desta pesquisa está na clareza das respostas dos alunos, que demonstram a importância das redes sociais para seus relacionamentos e que não são significativas para disseminação de conhecimento, somente de informações.

Cabe aos docentes incentivar e aderir às redes de seus alunos para levar e discutir informações sobre atualidades e principalmente para motivá-los no sentido de melhorar e ampliar os relacionamentos interpessoais entre os colegas de curso, mostrando que a caminhada acadêmica será muito mais gratificante se for coletiva.

\section{Referências Bibliográficas}

GIL, Antonio Carlos. Métodos e Técnicas de Pesquisa Social: $5^{\circ}$ edição. Atlas, São Paulo, 1999.

LUCCI, M. A. A proposta de Vygostsky: A psicologia sóciohistorica. Artigo publicado na Revista de currículum y formación del profesorado, Universidade de Granada, Espanha, 2006. LUNA, S.V. Planejamento de pesquisa. Educ, São Paulo, 2002.

VYGOTSKY, L.S. Obras Escogidas: problemas de psicologia geral. Gráficas Rogar. Fuenlabrada. Madrid, 1982.

VYGOTSKY,L.S. A formação social da mente: o desenvolvimento dos processos psicológicos superiores. 5.ed. Martins Fontes, São Paulo, 1996.

\section{SITES:}

http://www.bibliotecadigital.unicamp.br/document/?code=000789327 acesso em 22 de julho de 2011.

http://www.crmariocovas.sp.gov.br/dea_a.php?t=002 acesso em 03/02/2012.

http://www.ugr.es/ recfpro/rev102COL2port.pdf acesso em 03/02/2012. 